\title{
CPA Pass Rates in Texas: A 12-Year Analysis
}

\author{
Narita Holmes, Carol Sullivan \\ University of Texas of the Permian Basin, Texas, USA
}

\begin{abstract}
This research examines the CPA exam pass rates for higher education institutions in Texas. An investigation related to the top schools and AACSB accreditation is conducted as well as analyses related to public vs. private schools, area of the state where the institution is located, and University Systems. The results reflect impressive pass rates by University of Texas at Austin and Texas A\&M University at College Station in terms of both number of students taking the exam and the percentage passing it. There was a significant CPA rate lead with private universities only when the two outstanding public universities were omitted from the analysis. The research also found significant differences in terms of areas of the state as well as university systems. The analysis and the findings are very important to students with CPA exam success as their academic primary goal with their university education, the educational institutions preparing the students, and society as a whole. The findings may help guide both the universities and the students to better success with the exam as well as perhaps help taxpayers and legislators know how well tax money is being spent in this area.
\end{abstract}

Keywords: CPA pass rate success, educational performance, AACSB

\section{Introduction}

Both students and institutions involved with accounting education are usually very interested in CPA exam success, because it is the necessary requirement for licensure and long-term success in the public accounting profession. While there have been many studies related to CPA exam success, the data collected for those studies came from students self-reporting their institutions. This study uses one state's CPA exam performance information as reported by the Texas State Board of Public Accountancy (TSBPA) rather than the students' self-reported information provided by National Association of State Boards of Accountancy (NASBA). Additionally, the purpose of the research is to provide descriptive analyses related to AACSB accreditation and CPA exam success as well as public vs. private school, areas of the state, and University System differences.

\section{Research Background and Literature Review}

Allen and Woodland (2006), Read, Raghunandan, and Brown (2001), Whitten and Brahmasrene (2002), and Carpenter and Hock (2008) studied CPA exam pass rates as they relate to the 150-hour requirement, but their sample was taken before the exam became computerized. They found that candidates from more selective schools, candidates with advanced degrees, and candidates located in jurisdictions with the 150-hour requirement fully in place have higher pass rates. However, they found a significant decline in average pass rates during the 150-hour transition period. They also found only weak evidence of an association between program-level pass rates and college-level or separate AACSB accounting program accreditation. This current

Narita Holmes, Lecturer, Accounting, University of Texas of the Permian Basin. Email: Holmes_N@utpb.edu. Carol Sullivan, Associate Professor, Accounting, University of Texas of the Permian Basin. 
study investigates CPA exam pass rates in Texas, a state that had the 150-hour requirement during the entire 12 years studied, and also examines the CPA pass rates since the exam became computerized.

Bunker and Harris (2014) examined CPA exam success rates with online degrees and also made some comparisons between AACSB accredited schools and schools without that designation. Their results indicated that students from predominantly online accounting programs significantly underperform on the CPA exam. They also found that both AACSB and traditional, non-AACSB programs had significantly better CPA exam pass rates than the predominantly online accounting programs. While they used the NASBA data, this study uses data that are compiled by the TSBPA. There is a distinction because NASBA data are based on self-reporting of the candidates, while the TSBPA reviews the candidates' transcripts to determine the school designation for each candidate.

Howell and Heshizer (2008) studied characteristics of CPAs who passed the exam on the first or second attempt as compared to three or more attempts. They found that students who graduated from an AACSB-accredited institution were significantly more likely to pass in one or two attempts. Lindsay, Tan, and Campbell (2009) studied candidate performance on just the Business Environment section of the exam and their findings related to AACSB schools also reinforced the Howell and Heshizer study. Lindquist and Smith (2013), Lopez and Specht (2009), Paul (2004), Lasch (2005), and Akers, Giacomino, Courtney, and Johnson (2014) examined the top schools' success on the computerized exam as compared to the paper-and-pencil exam and found that there were some changes in the top schools with the new exam format. Barilla, Jackson, and Mooney (2008) compared exam success rates between AACSB schools and non-accredited schools and found that schools with the extra accounting accreditation performed better than the others. Raghunandan, Read, and Brown (2003) studied the impact of the 150-hour rule and found that the higher education standard had benefits to students, the CPA firms, and the profession. Ponemon and Schick (1998) had one element that cautioned people about using a professional certification as the primary exogenous variable for assessing the effectiveness of accounting programs and a reply that argued that the CPA exam is a standardized exam that is a reliable, valid, and robust test of certain core competencies. While this current research will not replicate these studies, it will contribute to the existing literature with more reliable data and more empirical testing of the issues found in these studies.

\section{Research Methodology}

Data were collected from the TSBPA website (http://www.tsbpa.state.tx.us/) where all of the Texas candidates must get approved before taking the exam. The TSBPA reports the CPA pass rate results by university on a quarterly basis - this represents the exam testing windows. The data collection is based on the first year that the TSBPA starting publishing the results and extends for 12 years; therefore, the research window is from 2004 to 2015.

\section{Results}

Table 1 reflects a listing of the Top 10 schools in terms of CPA pass rates in Texas. While the number of candidates passing from AACSB schools is quite significant, it is interesting to note that there are two schools without AACSB accreditation and only eight AACSB schools listed in this Top 10. There is also one community college found in this CPA exam pass rate honor roll. The asterisks next to the school names indicate that these schools are AACSB schools. Six of the Top 10 schools were AACSB schools, so a complete analysis of all schools was made with the AACSB vs. non-AACSB status examined. The AACSB schools' CPA exam 
performance was significantly better at the $p=0.02$ level. For both schools working hard to attain AACSB status and the AACSB organization itself, this finding is quite helpful. It is also interesting to note that six of the Top 10 schools are private schools; however, the number of students passing the CPA exam is dominated by the public universities of University of Texas-Austin and Texas A\&M University - College Station. These two schools account for $72 \%$ of the CPA exam parts taken and $74 \%$ of the CPA exam parts passed. This finding is particularly important to interested students and parents trying to make important decisions about where to attend college as well as taxpayers that are often paying the tuition bills for public higher education.

Table 1

\section{2-Year Texas CPA Exam Pass Rate Statistics (Top 10 Schools With 10 or More Parts Taken)}

\begin{tabular}{llrrl}
\hline \multirow{2}{*}{ No. } & School & \multicolumn{2}{c}{ 2004-2015 Totals } & All years \\
\cline { 3 - 3 } & & Taken & Passed & Passed (\%) \\
\hline 1 & Rice University $^{*}$ & 12 & 11 & $91.67 \%$ \\
3 & Tarrant Co. Community College $^{*}$ University of Texas-Austin $^{*}$ & 11 & 8 & $72.73 \%$ \\
4 & Texas A\&M - College Station $^{*}$ & 13,165 & 9,564 & $72.65 \%$ \\
5 & Baylor University $^{*}$ & 15,815 & 11,177 & $70.67 \%$ \\
6 & Southern Methodist University $^{*}$ & 5,056 & 3,238 & $64.04 \%$ \\
7 & Texas Christian University $^{*}$ & 3,602 & 2,296 & $63.74 \%$ \\
8 & Austin College $_{9}$ & 2,578 & 1,625 & $63.03 \%$ \\
10 & Sul Ross State University $^{\text {Southwestern Adventist }}$ & 40 & 25 & $62.50 \%$ \\
\hline
\end{tabular}

Note. ${ }^{*}$ indicates that this school is AACSB school.

Table 2 provides information related to whether private schools have significantly better performances than the public schools. This information is important because the cost of a private school education is significantly higher than public schools and the 150-hour requirement can create cost pressure for the students. It is interesting to note that the public schools had almost 5 times as many candidates as the private schools, but the private schools had a slightly higher CPA exam pass rate average overall. There was no statistical difference between the categories; however, people need to be aware that there were three public schools that had $0 \%$ success with CPA exam candidates over the 12-year period while there were no private schools with this type of record.

Table 2

Public vs. Private School Comparisons (With and Without University of Texas and Texas A\&M)

\begin{tabular}{lccc}
\hline Type of school & Parts taken & Passed & CPA pass rates \\
\hline \multicolumn{4}{c}{ With University of Texas and Texas A\&M University } \\
\hline Private & 23,372 & 12,300 & $52.63 \%$ \\
Public & 106,737 & 55,595 & $52.09 \%$ \\
\hline \multicolumn{4}{c}{ Without University of Texas and Texas A\&M University } \\
\hline Private & 23,372 & 12,300 & $52.63 \%$ \\
Public & 77,757 & 34,854 & $44.82 \%$ \\
\hline
\end{tabular}

Since University of Texas-Austin and Texas A\&M University have so many candidates, Table 2 also examines the public and private school comparisons without these two institutions. When this comparison was made, there was a significant difference (about 9\%) with the private schools outperforming the public institutions. Therefore, it might be helpful to attend a private school if the options of University of Texas-Austin and Texas A\&M University are not available. 
The state of Texas has several distinct areas in terms of education, business environment, and basic geography. Table 3 describes pass rates in terms of area (based on Texas Regional Maps ${ }^{1}$ ) categories. There were two areas that produced a pass rate greater than $60 \%$ and they are both found in the Central Texas area. However, they are also the areas that contain both University of Texas-Austin and Texas A\&M University; therefore, the significant success of these two universities may be skewing the areas' success rates. The lowest pass rates were found in the southeast region called the Coastal Bend area where the pass rate was only 34\%. Again, people in this area may need to consider going to an area that has better CPA exam pass rate performance as CPA exam success is their primary goal with respect to university education.

Since the University of Texas-Austin and Texas A\&M University were skewing the area results significantly, Table 3 also reflects a separate analysis of the areas with these two institutions omitted from the data. Again, Region 7 (the area with Texas A\&M University - College Station) had the best results with the greater than $60 \%$ success rate still intact. This was caused by the success of Baylor University, a strong private university in the region as well. Region 8 (the area with University of Texas-Austin) dropped significantly with the omission of UT-Austin and the results were just $51 \%$ without this school in the area.

Table 3

Areas of Texas Comparisons (With and Without University of Texas and Texas A\&M)

\begin{tabular}{|c|c|c|c|c|}
\hline No. & Area and top school in the area & Parts taken & Passed & CPA pass rates \\
\hline \multicolumn{5}{|c|}{ With University of Texas and Texas A\&M University } \\
\hline 1 & Texas Tech & 6,848 & 3,567 & $52.09 \%$ \\
\hline 2 & Abilene Christian & 3,087 & 1,560 & $50.53 \%$ \\
\hline 3 & Tarrant County Comm. College & 29,664 & 14,830 & $49.99 \%$ \\
\hline 4 & East Texas Baptist & 1,747 & 655 & $38.07 \%$ \\
\hline 5 & Stephen F. Austin & 3,608 & 1,454 & $40.30 \%$ \\
\hline 6 & Rice & 28,525 & 11,962 & $41.94 \%$ \\
\hline 7 & Texas A\&M - College Station & 20,873 & 14,416 & $69.07 \%$ \\
\hline 8 & University of Texas-Austin & 15,853 & 10,923 & $68.90 \%$ \\
\hline 9 & Trinity University & 13,488 & 5,989 & $44.40 \%$ \\
\hline 10 & Texas A\&M - International & 3,425 & 1,185 & $34.60 \%$ \\
\hline 11 & Sul Ross State University & 1,649 & 738 & $44.75 \%$ \\
\hline 12 & University of Texas - El Paso & 1,342 & 606 & $45.16 \%$ \\
\hline \multicolumn{5}{|c|}{ Without University of Texas and Texas A\&M University } \\
\hline 1 & Texas Tech & 6,848 & 3,567 & $52.09 \%$ \\
\hline 2 & Abilene Christian & 3,087 & 1,560 & $50.53 \%$ \\
\hline 3 & Tarrant County Comm. College & 29,664 & 14,830 & $49.99 \%$ \\
\hline 4 & East Texas Baptist & 1,747 & 655 & $38.07 \%$ \\
\hline 5 & Stephen F. Austin & 3,608 & 1,454 & $40.30 \%$ \\
\hline 6 & Rice & 28,525 & 11,962 & $41.94 \%$ \\
\hline 7 & Baylor & 5,058 & 3,239 & $64.04 \%$ \\
\hline 8 & Austin Community College & 2,688 & 1,359 & $50.56 \%$ \\
\hline 9 & Trinity University & 13,488 & 5,989 & $44.40 \%$ \\
\hline 10 & Texas A\&M - International & 3,425 & 1,185 & $34.60 \%$ \\
\hline 11 & Sul Ross State University & 1,649 & 738 & $44.75 \%$ \\
\hline 12 & University of Texas - El Paso & 1,342 & 606 & $45.16 \%$ \\
\hline
\end{tabular}

${ }^{1}$ Retrieved from http://www.wow.com/texasregionalmaps. 
The final analysis found in this research involves the University Systems in Texas. There are four University Systems in Texas: University of Texas, Texas A\&M, University of Houston, and Texas State University System. Table 4 compares the Systems to investigate whether there might be large-scale leadership goals helping with the CPA exam pass rate success. The Texas A\&M University System had the most best success rates with an overall average greater than $60 \%$ for the System. However, please note that one of their System schools had a $0 \%$ pass rate for the 10 -year period. The University of Texas System also experienced a success rate of almost 55\%, while the University of Houston and Texas State University Systems were somewhat comparable with each other at about $43 \%$.

Table 4

University Systems Comparisons

\begin{tabular}{lccl}
\hline University System & Parts taken & Passed & CPA pass rates \\
\hline Texas A\&M & 20,629 & 12,966 & $62.85 \%$ \\
University of Texas & 36,552 & 20,248 & $55.40 \%$ \\
Texas State University & 9,659 & 4,270 & $44.21 \%$ \\
University of Houston & 20,997 & 9,052 & $43.11 \%$ \\
\hline
\end{tabular}

Again, since the large numbers and excellent pass rate results can skew results, Table 5 reflects the University Systems' results with both University of Texas-Austin and Texas A\&M University omitted from the data. It is interesting to note that the University of Texas System went to the first place position, but the pass rate average decreased about $10 \%-46 \%$ with UT-Austin omitted. The most significant change took place with the Texas A\&M University System though. The System moved from the first place position to the last place position with Texas A\&M University - College Station omitted and the pass rate average decreased more than 25\%-37\% with the omission of just one institution. These results may be useful to Regents in the Systems who are interested in overall System success rather than just individual university success with the CPA exams.

Table 5

University Systems Comparisons (Without University of Texas-Austin and Texas A\&M University - College Station)

\begin{tabular}{lccl}
\hline University System & Parts taken & Passed & CPA pass rates \\
\hline University of Texas & 23,387 & 10,684 & $45.68 \%$ \\
Texas State University & 9,659 & 4,270 & $44.21 \%$ \\
University of Houston & 20,997 & 9,052 & $43.11 \%$ \\
Texas A\&M & 4,814 & 1,789 & $37.14 \%$ \\
\hline
\end{tabular}

\section{Concluding Remarks}

This study used more reliable reporting data and examined CPA exam pass rate success over a 10-year period for educational institutions in Texas. The research findings were that there were almost as many non-AACSB institutions found in the top school honor roll, but the AACSB schools had many more candidates. While there was no significant difference between public and private school CPA pass rate performance overall, the private schools performed much better when University of Texas-Austin and Texas A\&M - College Station exceptional performances were omitted from the analysis. Area of the state was also significant in terms of CPA exam success. Finally, the University System results reflected the superiority of the University of Texas A\&M University System; however, the Texas A\&M University System performances dropped drastically when 
the Texas A\&M University - College Station results were omitted from the analysis. The analysis and the findings are very important to students with CPA exam success as their academic primary goal with their university education, the educational institutions preparing the students, and society as a whole. The findings may help guide both the universities and the students to better success with the exam as well as perhaps help taxpayers and legislators know how well tax money is being spent in this area.

\section{References}

Akers, M., Giacomino, D., Courtney, K., \& Johnson, O. (2014). A profile of top performers on the uniform CPA exam. The CPA Journal, 84(8), 52-57.

Allen, A., \& Woodland, A. M. (2006). The 150-hour requirement and the number of CPA exam candidates, pass rates, and the number passing. Issues in Accounting Education, 21(3), 173-193.

Barilla, A. G., Jackson, R. E., \& Mooney, J. L. (2008). The CPA exam as a postcurriculum accreditation assessment. Journal of Education for Business, 83(5), 270-274.

Bunker, R. B., \& Harris, D. (2014). Online accounting degrees: An empirical investigation of CPA exam success rates. Journal of Business and Accounting, 7(1), 86-93.

Carpenter, C. G., \& Hock, C. A. (2008). The 150-hour requirement's effect on the CPA exam. The CPA Journal, 78(6), 62-64.

Howell, C., \& Heshizer, B. (2008). Characteristics that assist future public accountants pass the CPA exam on fewer attempts. The Journal of Applied Business and Economics, 8(3), 57-66.

Lasch, E. (2005). Pipeline into the profession: The electronic CPA exam one year later. Catalyst, 46-49.

Lindquist, T. M., \& Smith, G. (2013). Top schools' success on the computerized CPA exam. The CPA Journal, 83(5), 66-71.

Lindsay, D. H., Tan, K. B., \& Campbell, A. (2009). Candidate performance on the business environment and concepts section of the CPA exam. American Journal of Business Education, 2(7), 35-41.

Lopez, K., \& Specht, L. (2009). The computer-based CPA exam. The CPA Journal, 79(9), 64-70.

Paul, K. (2004). Different but good: New computerized CPA exam gets two thumbs up. Catalyst, 26-29.

Ponemon, L. A., \& Schick, A. G. (1998). Arguments against the CPA exam to gauge accounting program success. Issues in Accounting Education, 13(2), 421-428.

Raghunandan, K., Read, K. J., \& Brown, C. D. (2003). The 150-hour rule: Does it improve CPA exam performance? Managerial Auditing Journal, 18(1), 31-38.

Read, W. J., Raghunandan, K., \& Brown, C. (2001). 150-hour preparation improves CPA exam performance. The CPA Journal, 71(3), 30-34.

Whitten, D., \& Brahmasrene, T. (2002). Passing the uniform CPA exam: What factors matter? The CPA Journal, 72(11), 60-62. 